\title{
Prunustatin A, a Novel GRP78 Molecular Chaperone Down- regulator Isolated from Streptomyces violaceoniger
}

\author{
Yukiko Umeda, Shuhei Chijiwa, Kazuo Furihata, Keiko Furihata, Shohei Sakuda, \\ Hiromichi Nagasawa, Hidenori Watanabe, Kazuo Shin-ya
}

Received: October 18, 2004 / Accepted: February 14, 2005

(C) Japan Antibiotics Research Association

\begin{abstract}
In the course of our screening program for regulators of a molecular chaperone GRP78 expression, we isolated a novel inhibitor of GRP78 expression, designated as prunustatin A, from Streptomyces violaceoniger 4521SVS3. The structure of prunustatin A was determined by a series of NMR analyses to be an oxidized type of the neoantimycin family. Prunustatin A inhibited the expression of GRP78 induced by 2-deoxyglucose in human fibrosarcoma HT1080 cells accompanied by global cell death without showing cytotoxicity under normal nutrient condition.
\end{abstract}

Keywords molecular chaperone, GRP78, glucose deprivation, prunustatin

GRP78 acts as a molecular chaperone in the endoplasmic reticulum (ER) to promote protein folding. The enhancement of ER stress response has been proven to play a role in mechanisms of resistance to chemotherapy and hypoglycemic stress in solid tumor [1], while the reduction of ER stress response is involved in the pathology of central nervous diseases such as Alzheimer's and Parkinson's diseases [2]. The ER stress response causes an increase in gene expression of a number of ER chaperones such as GRP78/Bip and GRP94 [3]. Thus, substances that directly, either down- or up-regulate grp 78 transcription

K. Shin-ya (Corresponding author), Y. Umeda, S. Chijiwa, Keiko Furihata: Institute of Molecular and Cellular Biosciences, The University of Tokyo, Bunkyo-ku, Tokyo 113-0032, Japan, E-mail: kshin@iam.u-tokyo.ac.jp are expected to be promising drugs for the treatment of cancer and Alzheimer's disease, respectively. In the course of our screening program for regulators of GRP78/Bip molecular chaperone expression, we isolated versipelostatin [4] by employing a reporter gene assay system under the control of the GRP78 promoter. Further screening resulted in the isolation of a novel inhibitor of GRP78 expression, designated as prunustatin A (1, Figure 1), a new member of neoantimycin [5] family from an actinomycete identified as Streptomyces violaceoniger 4521-SVS3. In this paper, we report the fermentation of the producing organism and the isolation, physicochemical properties, structure elucidation and brief biological activities of prunustatin A.

The prunustatin producing strain was isolated from a soil sample collected on Kumejima island in Okinawa

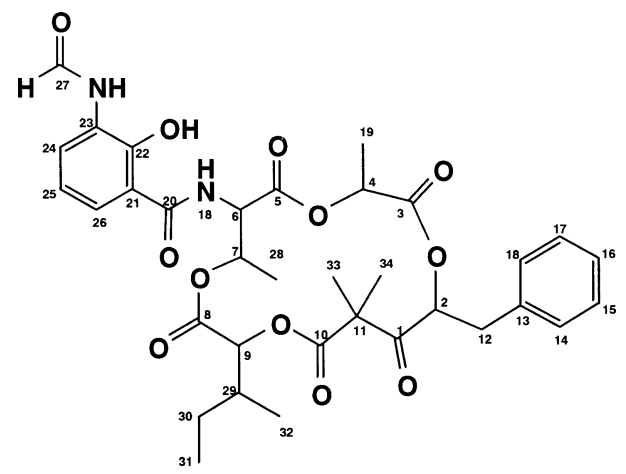

Fig. 1 Structure of prunustatin A (1). Graduate School of Agricultural and Life Sciences, The University of Tokyo, Bunkyo-ku, Tokyo 113-8657, Japan 
Table 1 Physico-chemical properties of prunustatin A (1)

\begin{tabular}{ll}
\hline Appearance & Pale yellow powder \\
Melting point & $103 \sim 106^{\circ} \mathrm{C}$ \\
{$[\alpha]_{D}^{27}\left(c 0.01, \mathrm{CHCl}_{3}\right)$} & $+21.2^{\circ}$ \\
Molecular formula & $\mathrm{C}_{34} \mathrm{H}_{40} \mathrm{~N}_{2} \mathrm{O}_{12}$ \\
HR-FABMS $(\mathrm{m} / \mathrm{z})$ & \\
& found: $669.2668[\mathrm{M}+\mathrm{H}]^{+}$ \\
UV $\lambda_{\max }(\mathrm{MeOH}) \mathrm{nm}(\varepsilon)$ & calcd: 669.2660 \\
IR $v_{\max }(\mathrm{KBr}) \mathrm{cm}^{-1}$ & $320(6480)$ \\
\hline
\end{tabular}

prefecture, and was subcultured on a Benett agar slant. It was cultivated in a seed medium consisting of starch $1.0 \%$, polypepton $1.0 \%$, molasses $1.0 \%$ and meat extract $1.0 \%$ (pH 7.2) for 2 days at $27^{\circ} \mathrm{C}$ on a rotary shaker. The seed culture was inoculated into 500-ml Erlenmeyer flasks each containing $100 \mathrm{ml}$ of the production medium composed of starch $2.5 \%$, soybean meal $1.5 \%$, dry yeast $0.2 \%$ and $\mathrm{CaCO}_{3}$ 0.4\% (pH 6.4 before sterilization), and these were cultivated on a rotary shaker $(200 \mathrm{rpm})$ for 5 days at $27^{\circ} \mathrm{C}$.

The fermented whole broth ( 2 liters) was centrifuged to obtain a mycelial cake, which was extracted with acetone (1 liter $\times 2$ ). The extract was concentrated in vacuo, and the residual aqueous solution was extracted twice with ethyl acetate. The separated organic layer was dried over $\mathrm{Na}_{2} \mathrm{SO}_{4}$, filtered and the filtrate was concentrated in vacuo. The active material was applied to a silica gel column packed with the solvent mixture of $n$-hexane and ethyl acetate $(2: 1)$. The column was developed with the same solvent system and active fractions were pooled and concentrated to dryness. The dry residue was rechromatographed on Sephadex LH-20 in $\mathrm{CHCl}_{3}-\mathrm{MeOH}$ (1:1). The active fraction was evaporated in vacuo to dryness and the residue was further purified by preparative HPLC using PEGASIL-ODS (Senshu Pak, 20 i.d. $\times 250 \mathrm{~mm}$ ) developed with $80 \%$ aqueous $\mathrm{MeOH}$ to give a pure sample of prunustatin A (1) as pale yellow powder.

The physico-chemical properties of $\mathbf{1}$ are summarized in Table 1. The molecular formula of $\mathbf{1}$ was established as $\mathrm{C}_{34} \mathrm{H}_{40} \mathrm{~N}_{2} \mathrm{O}_{12}$ on the basis of HRFAB-MS analysis. The direct connectivity of protons and carbons were established by the HMQC spectrum and the tabulated ${ }^{13} \mathrm{C}$ and ${ }^{1} \mathrm{H} N M R$ spectral data for $\mathbf{1}$ are shown in Table 2. The DQF-COSY and HMBC spectra established four partial structures (Fig. 2). The proton-proton correlations observed in the DQF-COSY include $14,18-\mathrm{H}\left(\delta_{\mathrm{H}} 7.03\right), 15,17-\mathrm{H}\left(\delta_{\mathrm{H}}\right.$ 7.23) and 16- $\mathrm{H}\left(\delta_{\mathrm{H}} 7.22\right)$ revealed the presence of a benzene ring moiety. The ${ }^{1} \mathrm{H}-{ }^{1} \mathrm{H}$ couplings between an oxymethine proton $2-\mathrm{H}\left(\delta_{\mathrm{H}} 5.66, \delta_{\mathrm{C}} 78.6\right)$ and methylene
Table $2{ }^{1} \mathrm{H}$ and ${ }^{13} \mathrm{C}$ NMR data for prunustatin $\mathrm{A}(\mathbf{1})$ in $\mathrm{CDCl}_{3}$

\begin{tabular}{|c|c|c|}
\hline No. & $\delta_{\mathrm{C}}$ & $\delta_{\mathrm{H}}$ \\
\hline 1 & 202.9 & \\
\hline 2 & 78.6 & $5.66(t, 6.0 \mathrm{~Hz})$ \\
\hline 3 & 168.3 & \\
\hline 4 & 69.9 & $5.40(q, 7.0 \mathrm{~Hz})$ \\
\hline 5 & 167.7 & \\
\hline 6 & 55.5 & $5.13(\mathrm{dd}, 9.0,2.0 \mathrm{~Hz})$ \\
\hline 7 & 71.4 & $5.85(\mathrm{dq}, 7.0,2.0 \mathrm{~Hz})$ \\
\hline 8 & 168.4 & \\
\hline 9 & 76.2 & $4.78(\mathrm{~d}, 8.0 \mathrm{~Hz})$ \\
\hline 10 & 172.1 & \\
\hline 11 & 54.4 & \\
\hline \multirow[t]{2}{*}{12} & 36.9 & $3.32(\mathrm{dd}, 14.0,6.0 \mathrm{~Hz})$ \\
\hline & & $3.24(\mathrm{dd}, 14.0,6.0 \mathrm{~Hz})$ \\
\hline 13 & 135.0 & \\
\hline 14,18 & 129.9 & $7.03(2 \mathrm{H}, \mathrm{dd}, 8.0,2.0 \mathrm{~Hz})$ \\
\hline 15,17 & 128.5 & $7.23(2 \mathrm{H}, \mathrm{m})$ \\
\hline 16 & 127.3 & $7.22(\mathrm{~m})$ \\
\hline 19 & 17.5 & $1.43(3 \mathrm{H}, \mathrm{d}, 7.0 \mathrm{~Hz})$ \\
\hline 20 & 170.3 & \\
\hline 21 & 112.8 & \\
\hline 22 & 150.6 & \\
\hline 23 & 127.3 & \\
\hline 24 & 124.8 & $8.55(\mathrm{dd}, 8.0,1.0 \mathrm{~Hz})$ \\
\hline 25 & 119.0 & $6.93(t, 8.0 \mathrm{~Hz})$ \\
\hline 26 & 120.5 & $7.37(\mathrm{~d}, 8.0 \mathrm{~Hz})$ \\
\hline 27 & 158.9 & 8.49 (s) \\
\hline 28 & 16.7 & $1.29(3 \mathrm{H}, \mathrm{d}, 7.0 \mathrm{~Hz})$ \\
\hline 29 & 36.2 & $1.92(\mathrm{~m})$ \\
\hline \multirow[t]{2}{*}{30} & 24.6 & 1.46 (m) \\
\hline & & $1.16(\mathrm{~m})$ \\
\hline 31 & 10.5 & $0.84(3 \mathrm{H}, \mathrm{d}, 7.0 \mathrm{~Hz})$ \\
\hline 32 & 14.4 & $0.86(3 \mathrm{H}, \mathrm{d}, 7.0 \mathrm{~Hz})$ \\
\hline 33 & 22.2 & $1.28(3 \mathrm{H}, \mathrm{s})$ \\
\hline 34 & 20.7 & $1.02(3 \mathrm{H}, \mathrm{s})$ \\
\hline 23-NH & & 7.90 (s) \\
\hline $6-\mathrm{NH}$ & & $7.16(d, 9.0 \mathrm{~Hz})$ \\
\hline
\end{tabular}

${ }^{1} \mathrm{H}$ and ${ }^{13} \mathrm{C}$ NMR were observed at 500 and $125 \mathrm{MHz}$, respectively.

protons $12-\mathrm{H}\left(\delta_{\mathrm{H}} 3.32,3.24\right)$, together with ${ }^{1} \mathrm{H}-{ }^{13} \mathrm{C}$ longrange couplings in $\mathrm{HMBC}$ spectrum from $2-\mathrm{H}, 12-\mathrm{H}$ and $15,17-\mathrm{H}$ to $\mathrm{C}-13\left(\delta_{\mathrm{C}} 135.0\right), 14-\mathrm{H}$ and $18-\mathrm{H}$ to $\mathrm{C}-12$ $\left(\delta_{\mathrm{C}} 36.9\right)$ established the phenethyl residue. The protons of two singlet methyl groups $33-\mathrm{H}\left(\delta_{\mathrm{H}} 1.28\right)$ and $34-\mathrm{H}$ $\left(\delta_{\mathrm{H}} 1.02\right)$ were each long-range coupled to an ester carbonyl carbon C-10 $\left(\delta_{\mathrm{C}} 172.1\right)$, a quaternary carbon C-11 $\left(\delta_{\mathrm{C}} 54.4\right)$ and a ketone carbonyl carbon C-1 $\left(\delta_{\mathrm{C}} 202.9\right)$, which in turn long-range coupled to $2-\mathrm{H}$. These HMBC 


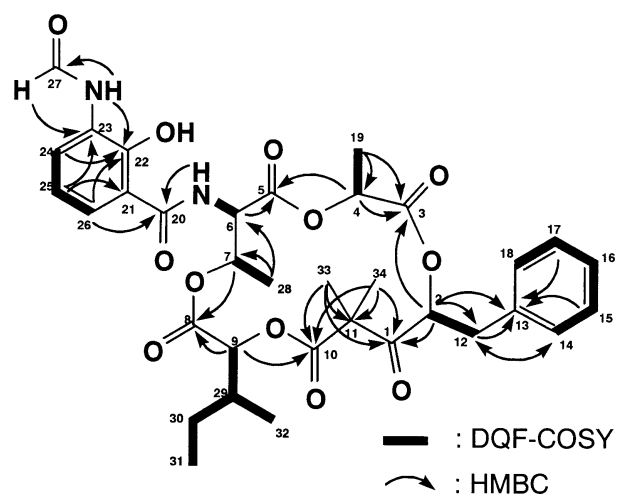

Fig. 2 DQF-COSY and HMBC analyses of 1.

correlations indicated the successive connectivity of C-2, $\mathrm{C}-1$ and $\mathrm{C}-11$ as shown in Figure 2. Thus, a 4-hydroxy2,2-dimethyl-3-oxo-5-phenylpentanoic acid moiety was elucidated as a partial structure of $\mathbf{1}$ as shown in Figure 2. A 2-hydroxypropionic acid moiety was established by ${ }^{1} \mathrm{H}-{ }^{1} \mathrm{H}$ correlation between an oxymethine proton $4-\mathrm{H}$ $\left(\delta_{\mathrm{H}} 5.40, \delta_{\mathrm{C}} 69.9\right)$ and a methyl proton $19-\mathrm{H}\left(\delta_{\mathrm{H}} 1.43\right)$, and ${ }^{1} \mathrm{H}-{ }^{13} \mathrm{C}$ long-range correlations between $19-\mathrm{H}$ and $\mathrm{C}-3$ $\left(\delta_{\mathrm{C}} 168.3\right)$.

The proton sequence between the aromatic protons $24-\mathrm{H}$ $\left(\delta_{\mathrm{H}} 8.55\right), 25-\mathrm{H}\left(\delta_{\mathrm{H}} 6.93\right)$ and $26-\mathrm{H}\left(\delta_{\mathrm{H}} 7.37\right)$ indicated a $1,2,3$-trisubstituted benzene ring moiety. An amide proton 23-NH $\left(\delta_{\mathrm{H}} 7.90\right)$ was long-range coupled to an aldehyde carbon C-27 $\left(\delta_{\mathrm{C}} 158.9\right)$, which was considered to connect directly with this amide nitrogen atom from its ${ }^{13} \mathrm{C}$ chemical shift. The aldehyde proton $27-\mathrm{H}\left(\delta_{\mathrm{H}} 8.49\right)$ and the aromatic proton $25-\mathrm{H}$ were long-range coupled to an aromatic carbon $\mathrm{C}-23\left(\delta_{\mathrm{C}} 127.3\right)$. These results suggested that the formylamino group was substituted at the C-23 position. The aromatic proton $26-\mathrm{H}$ was long-range coupled to a carbonyl carbon C-20 $\left(\delta_{\mathrm{C}} 170.3\right)$ at the peri position, which indicated that this carbonyl carbon was substituted at $\mathrm{C}-21$. The aromatic protons $24-\mathrm{H}$ and $26-\mathrm{H}$ in addition to an amide proton $23-\mathrm{NH}\left(\delta_{\mathrm{H}} 7.90\right)$ were long-range coupled to $\mathrm{C}-22\left(\delta_{\mathrm{C}} 150.6\right)$. By taking into consideration these ${ }^{13} \mathrm{C}$ chemical shifts of aromatic carbons, an oxygen atom should be substituted at the C-22 position. The UV spectrum of $\mathbf{1}$ also suggested the existence of the 2-hydroxy-3-formylamino-benzoic acid moiety, which is the same chrmophore as that of the antimycins $[6,7]$. An amide proton $6-\mathrm{NH}\left(\delta_{\mathrm{H}} 7.16\right)$ was coupled with $6-\mathrm{H}\left(\delta_{\mathrm{H}} 5.13\right)$ which is considered to be an $\alpha$-methine proton of an amino acid residue from its typical ${ }^{13} \mathrm{C}$ chemical shift $\left(\delta_{\mathrm{C}} 55.5\right)$. A methyl proton $28-\mathrm{H}$ $\left(\delta_{\mathrm{H}} 1.29\right)$, which was coupled with an oxymethine proton 7-H $\left(\delta_{\mathrm{H}} 5.85\right)$, was long-range coupled to $\mathrm{C}-6$ and $\mathrm{C}-7$ $\left(\delta_{\mathrm{C}} 71.4\right)$. In addition to these correlations, the long-range couplings from the methine proton $6-\mathrm{H}$ to a carbonyl carbon $\mathrm{C}-5\left(\delta_{\mathrm{C}} 167.7\right)$, and from the amide proton $6-\mathrm{NH}$ to $\mathrm{C}-20$ were observed. These results indicated the threonine residue and the connectivity with the chromophore moiety.

The remaining substructure was also determined by the interpretation of ${ }^{1} \mathrm{H}-{ }^{1} \mathrm{H}$ spin couplings and ${ }^{1} \mathrm{H}-{ }^{13} \mathrm{C}$ long-range couplings as follows. The long-range coupling between $9-\mathrm{H}\left(\delta_{\mathrm{H}} 4.78\right)$ and a carbonyl carbon $\mathrm{C}-8\left(\delta_{\mathrm{C}}\right.$ $168.4)$, along with the sequence from $9-\mathrm{H}$ to $31-\mathrm{H}\left(\delta_{\mathrm{H}}\right.$ $0.84)$ through $29-\mathrm{H}\left(\delta_{\mathrm{H}} 1.92\right)$, which was additionally coupled to a methyl proton $32-\mathrm{H}\left(\delta_{\mathrm{H}} 0.86\right)$, and $30-\mathrm{H}$ $\left(\delta_{\mathrm{H}} 1.16,1.46\right)$ observed in the DQF-COSY spectrum of $\mathbf{1}$ established a 2-hydroxy-3-methylpentanic acid moiety as shown in Figure 2. The connectivity of these partial structures were elucidated by the long-range couplings between 2-H and $\mathrm{C}-3,4-\mathrm{H}$ and $\mathrm{C}-5,7-\mathrm{H}$ and $\mathrm{C}-8$, and 9-H and $\mathrm{C}-10$. In this manner, the structure of $\mathbf{1}$ was determined as shown in Figure 1. As an analog of prunustatin A with a 15-membered macrocyclic, SW-163A, which can be considered as a reduced type of prunustatin $\mathrm{A}$ at the C-1 position, has been reported as an immunosuppressant [8].

The human fibrosarcoma cell line HT1080 cells which were transformed with the luciferase reporter gene under the regulation of the GRP78 promoter (designated as HT1080 G-L), produced luciferase in four times greater quantity than did the control when treated with $10 \mathrm{mM}$ of 2-deoxyglucose (2-DG). In this evaluation system employed as a screen, prunustatin A reduced the expression of the reporter gene with an $\mathrm{IC}_{50}$ value of $11.5 \mathrm{nM}$. In the same manner, the structurally related compound SW-163 A [8], which was also produced by the prunustatin producing strain, exhibited inhibitory activity in this assay with an $\mathrm{IC}_{50}$ value of $22.9 \mathrm{nM}$. Prunustatin A completely inhibited the expression of GRP78 at the protein level at the concentrations of more than $80 \mathrm{nM}$ in HT1080 cells without affecting actin level. Under normal condition, prunustatin A showed cytostatic effect but not exhibited cytotoxicity even at the concentration of $500 \mathrm{nM}$. On the other hand, prunustatin A treatment became highly toxic in 2-DG containing medium resulting in approximately six times greater cell death ratio at the concentration of $100 \mathrm{nM}$ than that in normal conditioned medium.

Since SW-163A showed the similar activity to $\mathbf{1}$, the redox state at the $\mathrm{C}-1$ position is not essential for this biological activity. Although the chromophore of $\mathbf{1}$ is same as that of antimycins [6,7], which has a 9-membered macrocyclic substructure, it is interesting that prunustatin A is stable to oxidative insult, contrary to the vulnerability of antimycins to oxidative and acidic condition. As observed with versipelostatin [9], prunustatin A induced global cell death under glucose deprived condition such as 
the treatment with 2-DG but not under normal nutrient conditions. Thus, it is expected that prunustatin A would be a useful cancer chemotherapeutic agent against solid tumors. Studies on the elucidation of the absolute structure and detailed biological activities of $\mathbf{1}$ are now underway.

Acknowledgments This work was supported in part by Industrial Technology Research Grant Program in 01A04006b from New Energy and Industrial Technology Development Organization (NEDO) of Japan.

\section{Reference}

1. Katschinski DM, Jacobson EL, Wiedemann GJ, Robins HI. Modulation of VP-16 cytotoxicity by carboplation and 41. $8^{\circ} \mathrm{C}$ hyperthermia. Cancer Res Clin Oncol 127: 425-435 (2001)

2. Imaizumi K, Miyoshi K, Katayama T, Yoneda T, Taniguchi M, Kubo T, Tohyama M. The unfolded protein response and Alzheimer's disease. Biochim Biophys Acta 1536: 85-96 (2001)
3. Kaufman RJ. Stress signaling from the lumen of the endoplasmic reticulum: coordination of gene transcriptional and translational controls. Genes Dev 13: 1211-1233 (1999)

4. Park HR, Furihata K, Hayakawa Y, Shin-ya K. Versipelostatin, a novel GRP78/Bip molecular chaperone down-regulator of microbial origin. Tetrahedron Lett 43: 6941-6945 (2002)

5. Caglioti L, Misiti D, Mondelli R, Selva A, Arcamone F, Cassinelli G. The structure of neoantimycin. Tetrahedron 25: 2193-2221 (1969)

6. Watanabe K, Tanaka T, Fukuhara K, Miyairi N, Yonehara H, Umezawa H. Blastmycin: a new antibiotic from Streptomyces sp. J Antibiot 10A: 39-45 (1957)

7. Kinoshita M, Wada M, Umezawa S. The total syntheses of a diastereomeric mixture of antimycin A3 (blastmycin). J Antibiot 22: 580-582 (1969)

8. Takahashi K, Tsuda E, Kurosawa K. SW-163A and B, novel immunosuppressants produced by Streptomyces sp. J Antibiot 54: 867-873 (2001)

9. Park HR, Tomida A, Sato S, Tsukumo Y, Yun J, Yamori T, Hayakawa Y, Tsuruo T, Shin-ya K. Blockade of survival response to glucose deprivation for selective killing of tumor cells. J Natl Can Inst 96: 1300-1330 (2004) 